\title{
“Juntas nos quitamos el miedo". Estudiantes feministas contra la violencia sexista
}

Araceli Mingo

\section{RESUMEN}

Con el propósito de conocer el trabajo realizado por estudiantes feministas cuyas colectivas hicieron suya la tarea de denunciar la violencia machista ocurrida en diversos espacios de la Universidad Nacional Autónoma de México, solicité la participación de 11 de ellas para esta investigación. El análisis de la información recolectada en las entrevistas que me concedieron, así como en otras fuentes, permiten apreciar, entre otras cosas, la importante labor que han cumplido con el acompañamiento brindado a quienes han sufrido tal tipo de violencia, así como al hacer visible la presencia continuada de ésta dentro de una institución en la que, al igual que sucede en casi todas las universidades, esa conducta se ha normalizado.

Palabras clave: educación superior, estudiantes feministas, violencia sexista, acoso sexual, movimientos estudiantiles, México.

\section{Araceli Mingo}

mingo@unam.mx

Mexicana. Doctora en Investigación Psicológica, Universidad Iberoamericana. Investigadora titular del Instituto de Investigaciones sobre la Universidad y la Educación (IISUE) y profesora de la Facultad de Filosofía y Letras de la Universidad Nacional Autónoma de México (UNAM). Temas de investigación: relaciones de género en instituciones de educación superior. 


\title{
“Juntas eliminamos o medo”. Estudantes feministas contra a violência sexista
}

\section{RESUMO}

Com o propósito de conhecer o trabalho realizado por estudantes feministas cujas coletivas tomaram a tarefa de denunciar a violência machista ocorrida em diversos espaços da Universidad Nacional Autónoma de México, solicitei a participação de 11 delas para esta pesquisa. A análise da informação coletada nas entrevistas que me concederam, assim como em outras fontes, permitem reconhecer, entre outras coisas, o importante trabalho que têm cumprido com o acompanhamento dado àquelas que sofreram tal tipo de violência, assim como ao fazer visível a presença continuada desta dentro de uma instituição na que, assim como acontece em quase todas as universidades, essa conduta tem-se normalizado.

Palavras chave: educação superior, estudantes feministas, violência sexista, assédio sexual, movimentos estudantis, México.

\section{“Together we take away the fear." Feminist Students Against Sexist Violence}

\begin{abstract}
In order to learn about the work carried out by feminist students whose groups took on the task of denouncing the macho violence that occurred in various spaces at the National Autonomous University of Mexico, the author requested in this research the participation of 11 of them. The analysis of the information that was gathered during the interviews, as well as other sources, allows to appreciate, among other things, the important work they have done in accompanying those who have suffered such violence, as well as in making visible the constant presence of such violence within an institution where, as is the case in almost all higher education institutions, such behavior has become normalized.
\end{abstract}

Key words: higher education, feminist students, sexist violence, sexual harassment, student movements, Mexico. 


\section{Violencia sexista en instituciones de educación superior}

La superioridad de las características consideradas como masculinas con respecto a las características identificadas como femeninas está en la base de los mitos en los que en diversos momentos históricos y culturas las mujeres aparecen representadas como intelectual, fisica y psíquicamente inferiores a los hombres. También tomando "su naturaleza" como referente, en algunos mitos se les ha representado como poseedoras de cualidades peligrosas para la fortaleza de los hombres, tales como ser seductoras, astutas, carnales, curiosas. De esta forma, ya sea por sus supuestas múltiples fragilidades o por su peligrosidad, el control de las mujeres, de su cuerpo y de su campo de acción se impuso como tarea masculina (véase Gilmore, 2001; Holland, 2010).

Respecto a la eficacia de los mitos Fernández (1993: 78 y 89) señala que, en tanto cristalizaciones de sentido, la eficacia de los mitos en el disciplinamiento social y en la legitimación y el orden de las instituciones que involucran, obedece a que a través de la repetición de sus narrativas naturalizan las significaciones que los propios mitos instituyen. Es mediante este mecanismo que las realidades que son producto y efecto de su eficacia aparecen como naturales y ahistóricas, y por lo mismo inmodificables.

La relevancia de la imposición de sentidos en la vida de los sujetos se aprecia en el concepto de violencia simbólica desarrollado por Bourdieu (1999: 173) "La violencia simbólica es esa violencia que arranca sumisiones que ni siquiera se perciben como tales apoyándose en unas 'expectativas colectivas', en unas creencias socialmente inculcadas". En el mismo sentido, Héritier (2007: 84-85) plantea:

En efecto, la dominación masculina existe; es efectiva, opresora, violenta, en muchas sociedades de nuestro mundo contemporáneo, pero también, de manera menos notoria, simbólica, inculcada desde la infancia en los ritos y los imaginarios masculinos y femeninos que funcionan de manera evidente, como algo natural y obvio [...] Y siempre, inculcadas profundamente en las mujeres, están las inquietudes, las dudas y las incertidumbres respecto de sus capacidades, su legitimidad y su dignidad, aun cuando lleguen - se sabe que con dificultades - a altas posiciones intelectuales o profesionales, tradicionalmente consideradas como masculinas. Esta inquietud tal vez no sea la marca de la violencia más brutal, pero por su insidioso arraigo progresivo en el espíritu desde la infancia, es por cierto la más profunda.

A propósito del papel del sistema socializador del patriarcado en el sostenimiento de éste, Millet señala:

No estamos acostumbrados a asociar el patriarcado con la fuerza. Su sistema socializador es tan perfecto, la aceptación general de sus valores tan firme y su historia en la sociedad humana tan larga y universal, que apenas necesita el respaldo de la violencia. Por lo común, sus brutalidades pasadas nos parecen prácticas exóticas o "primitivas" y las actuales, extravíos individuales, patológicos o excepcionales, que carecen de significado colectivo. Y, sin embargo, al igual que otras ideologías dominantes, como el racismo y el colonialismo, la sociedad patriarcal ejercería un control insuficiente, e incluso ineficaz, de no contar con el apoyo de la fuerza, que no sólo constituye una medida de excepcionalidad, sino también un instrumento de intimidación constante (Millet, 1995: 100).

$\mathrm{Al}$ igual que sucede en cualquier espacio social, las modalidades que adopta la violencia sexista en las instituciones de educación superior (IES) son variadas. ${ }^{1}$ Diversos estudios dan cuenta de la importante

\footnotetext{
${ }^{1}$ Si bien las estudiantes entrevistadas aluden a las violencias que sufren por parte de los varones como violencias machistas, en este trabajo se utilizan indistintamente los términos "violencia sexista" y "violencia machista". Violencia que transita desde formas sutiles y escurridizas que marcan de alguna manera a las mujeres como inferiores a los varones (débiles, pasivas, inestables, etcétera), hasta actos de violencia extrema como violaciones y feminicidios.
} 
magnitud que alcanza dentro de éstas uno de los comportamientos que resulta particularmente intimidatorio: la violencia sexual —ya sea acoso (atención sexual no deseada como comentarios sobre el cuerpo, miradas morbosas) o cualquier tipo de contacto o actividad de carácter sexual que ocurre sin el consentimiento de la persona afectada. ${ }^{2}$ Violencia que por los efectos de diversa naturaleza que acarrea a quienes la sufren ${ }^{3}$ o por la amenaza que representa la posibilidad de sufrir comportamientos de este tipo, opera como mecanismo de control del cuerpo y campo de acción de las mujeres.

El riesgo que tienen las estudiantes de ser objeto de violencia sexual se hace evidente en datos como los siguientes: el estudio realizado en 27 reconocidas universidades de Estados Unidos muestra que la proporción de alumnas que había sufrido acoso sexual se distribuía en un rango de $49 \%$ a $74 \%$ (Cantor et al., 2015: XVI); en Australia, 63\% de las participantes en una encuesta realizada en 39 universidades habían padecido por lo menos un acto de acoso sexual durante 2016 y 32\% había sido acosada dentro de los espacios universitarios (AHRG, 2017: 36); alrededor de $60.7 \%$ de las alumnas de 35 universidades de cinco países europeos (Alemania, España, Italia, Polonia, Reino Unido) reportó al menos una instancia de acoso sexual (Feltes, 2012: 59); en cuatro universidades públicas del sureste mexicano se encontró que del $40 \%$ de estudiantes que habían experimentado acoso sexual en su escuela en el último año, 69\% eran mujeres (Evangelista, 2017: 337); Buquet et al. (2014: 304-305) identificaron que $49.3 \%$ de las alumnas había padecido durante los dos últimos semestres cursados algún acto de acoso sexual dentro de la Universidad Nacional Autónoma de México (UNAM).
En contraste con los altos porcentajes señalados, vemos que la denuncia formal de estos actos es muy reducida. Por ejemplo, en el caso de las universidades estadounidenses sólo 9.1\% de las estudiantes hizo un reporte en su institución (Cantor et al., 2015: 112); en las australianas 95\% no lo reportó (AHRC, 2017: 120); en la UNAM únicamente 2.9\% presentó una queja (Buquet et al., 2014: 308).

$\mathrm{El}$ sofocamiento de las denuncias relativas a actos de violencia sexual contra las mujeres y el silenciamiento de este fenómeno en las IES es un hecho común (véase Ahmed, 2015; Phipps, 2017, 2018; Whitley y Page, 2015; Dick, 2015; Barreto, 2017, 2018). A propósito de su trabajo de muchos años en universidades de diversos países, Phipps señala que en las IES el acoso y las agresiones sexuales se esconden bajo el tapete por lo que el acto de revelar tiene una carga emocional muy fuerte y a menudo resulta amenazante. Revelar, dice ella, es exponer, nombrar algo que crea malestar y vergüenza. Agrega que nos exponemos cuando revelamos lo que nos ha ocurrido, pero también tenemos el potencial de exponer a quienes nos han lastimado a nivel individual e institucional. Añade que tenemos temor a exponernos pero que tal vez nos da mayor temor el exponer a quienes realizan estos actos por las consecuencias que acarrea; el solo pensamiento de esto puede ser suficiente para evitar hacer una revelación (Phipps, 2016).

Respecto a los factores que favorecen la ruptura del silencio, Vidu et al. (2017: 5) señalan que para que las víctimas se atrevan a dar un paso adelante necesitan sentirse empoderadas, lo cual requiere que dispongan de apoyo social, por ejemplo, de quienes se solidarizan con ellas, pues de otro modo se mantendrán aisladas y no se atreverán a combatir por lo ocurrido. En relación con la necesidad de sistemas

\footnotetext{
${ }^{2}$ En el artículo de Fuentes (2019) se pueden apreciar ejemplos variados de las modalidades que adopta el acoso sexual. Asimismo, en el número monográfico sobre "Violencias de género en las universidades" de la revista Nómadas, editado por Fuentes, Jiménez y Villar (2019), se pueden consultar los resultados de investigaciones sobre acoso realizadas en distintos países de América Latina.

${ }^{3}$ Para ejemplos de los impactos en la salud mental, en los estudios y la carrera, así como en la vida social, véase Australian Human Rights Commission (AHRC) (2017: 98-100); National Academies of Sciences, Engineering and Medicine (2018: 67-78).
} 
de soporte, considérese la inversión emocional que demanda hacer una denuncia, superar aspectos tales como la vergüenza, la ansiedad, la depresión, el miedo al descrédito o a las represalias; es decir, las variadas tensiones que generan tanto la experiencia vivida como las reacciones negativas que muchas veces acarrea la denuncia de estos actos.

Por ello, el empeño puesto por diversas colectivas de estudiantes feministas en hacer visible que el acoso y las agresiones sexuales que ocurren en los espacios universitarios están lejos de ser "extravíos individuales, patológicos o excepcionales, que carecen de significado colectivo" (Millet, 1995: 100), así como el acompañamiento brindado a las estudiantes que han sufrido estas conductas adquiere, como se verá más adelante, gran relevancia.

\section{Acerca de este estudio}

Esta investigación surgió con el propósito de conocer el trabajo realizado por estudiantes feministas cuyas colectivas hicieron suya la tarea de denunciar la violencia machista ocurrida en diversos espacios universitarios, así como la de dar acompañamiento a las afectadas. El primer acercamiento a ellas tuvo como origen la visibilidad que adquirió en 2016 la Asamblea Feminista (AF), colectiva que surgió ese año debido al malestar de un grupo de alumnas de la Facultad de Filosofía y Letras (FFL) por el acoso y comportamiento machista de sus compañeros, tanto en las organizaciones estudiantiles como en la vida cotidiana en la facultad.

Mi interés por conocer las inquietudes de este grupo de activistas y sus formas de trabajo me condujo a asistir a las asambleas y actividades que organizaban para dar visibilidad amplia a su lucha. Esto me permitió, además de registrar lo que observaba en éstas, tomar contacto con varias de ellas que, después de consultarlo en su colectiva, aceptaron participar como informantes para esta investigación. Por otro lado, el conocimiento que tenía de la lucha que desde 2011 desarrollaba la Red No Están Solas me llevó a acercarme a algunas de sus integrantes que accedieron a ser entrevistadas. Asimismo, solicité el apoyo de otras estudiantes que también tenían experiencia como activistas en grupos exclusivos de mujeres interesados en poner un alto a la violencia machista. De esta forma, la elección del conjunto de las entrevistadas obedeció a su experiencia en colectivas feministas que luchaban por la erradicación de este tipo de violencia.

Las entrevistas fueron semiestructuradas, tuvieron una duración promedio de dos horas, se grabaron y transcribieron para su posterior análisis. Previo a la realización de cada una, se informó a las participantes sobre el uso que se iba a dar a la información que proporcionaran para solicitar su acuerdo. La guía de entrevista tiene dos grandes apartados. En el primero se indagaba acerca del surgimiento y trayectoria de las colectivas en las que participaban las estudiantes, su vida interna, estrategias de acción y frutos de su trabajo; en el segundo se recogían los datos sociodemográficos de las estudiantes, así como la información referida tanto a su historia personal como a la de su participación en colectivas feministas. Para el análisis de la información que se presenta en este artículo se consideró lo relativo a sus formas de protesta, las experiencias vividas por las estudiantes en sus movilizaciones, la dimensión emocional de su trabajo, y los frutos de éste. Para el procesamiento de la información se utilizó la técnica de análisis temático (Braun y Clarke, 2012, entre otros). Con objeto de mantener el anonimato de las informantes, sus nombres fueron cambiados. Mi agradecimiento para ellas por su generosidad y por todo lo aprendido en cada una de sus historias.

En el siguiente cuadro se presentan los datos correspondientes a la edad y estudios de las entrevistadas. Se identifica con $\mathrm{AF}+$ a quienes además de formar parte de la AF participaban en otras colectivas, con RED a las integrantes de la Red No Están Solas y se dejan en blanco los nombres de las colectivas a las que pertenecían las otras informantes. 
Cuadro 1. Participantes en el estudio

\begin{tabular}{|l|c|l|c|}
\hline Luisa & 25 años & Último semestre de licenciatura & AF+ \\
\hline Rosa & 25 años & Último semestre de licenciatura & AF+ \\
\hline Elvira & 21 años & Último semestre de licenciatura & AF+ \\
\hline María & 20 años & Sexto semestre de licenciatura & AF \\
\hline Susana & 24 años & Último semestre de licenciatura & AF+ \\
\hline Sofía & 22 años & Último semestre de licenciatura & AF+ \\
\hline Margarita & 26 años & Tesis de licenciatura en proceso & \\
\hline Estela & 32 años & Posgrado & RED \\
\hline Elena & 35 años & Posgrado & \\
\hline Elsa & 33 años & Posgrado & RED \\
\hline Teresa & 35 años & Posgrado & \\
\hline
\end{tabular}

Fuente: elaboración propia.

\section{Surgimiento de las colectivas}

La Asamblea Feminista surge en mayo de 2016 como resultado de la inconformidad de un pequeño grupo de alumnas por el trato que se dio en una asamblea mixta al acoso sexual sufrido por una de ellas de parte de uno de los asistentes. El enojo que generó en varias estudiantes - que ya se identificaban como feministas - el que la demanda que hicieron a la mesa para que se expulsara de la asamblea al agresor no fuera atendida, las llevó a reunirse al final de ésta para comentar lo ocurrido. Fue así que decidieron formar una colectiva exclusiva de mujeres que se ocuparía de dar atención a las diversas formas de violencia machista que vivían en la FFL.

María comenta que en la primera asamblea pública que organizó la AF se acordó crear una red para que las estudiantes pudieran comunicarse y convocar acciones para denunciar lo que ocurría dentro de la FFL. En la página de Facebook que abrieron para dar a conocer su grupo se publicó un comunicado en el que se precisa: "[Esta colectiva] está organizada por mujeres y para mujeres. Esto significa que no aceptamos la participación directa ni indirecta - aplausos y silbidos claramente [mal] intencionados- de hombres". También se señala que en la primera asamblea pública que realizaron se conocieron diversos casos de acoso sexual ocurridos en la facultad y se evidenció la necesidad de discutir sobre las violencias machistas. Agregan que esto condujo a la propuesta de acciones para hacer frente "a la situación invisibilizada en la que todas vivimos" dentro y fuera de la universidad: "chistes machistas, comentarios misóginos, acoso en las aulas y en los pasillos de parte de compañeros, docentes, personal [administrativo] y trabajadores, mansplaining, ${ }^{4}$ amedrentamiento, humillación e intimidación". También manifiestan su inconformidad con las jerarquías que se hacen patentes en las asambleas estudiantiles mixtas en las que las mujeres "somos calladas, ignoradas, violentadas, acosadas, ridiculizadas". ${ }^{5}$

\footnotetext{
${ }^{4}$ Las explicaciones en tono condescendiente que dan hombres a mujeres sobre algún asunto y con las que se sugiere que ellas tienen un conocimiento o una comprensión inferior a ellos en la materia en cuestión (para profundizar en este comportamiento, véase: http:// www.tomdispatch.com/post/174918/).

${ }^{5}$ https://www.facebook.com/Feministas-de-FFyL-1537475649892416/ [Consulta: agosto de 2016].
} 
La Red No Están Solas (REDNES) tiene como antecedente un grupo de autorreflexión o pequeño grupo formado en 2009 por seis estudiantes que leían textos feministas y discutían sus experiencias e inquietudes personales. Cuando en 2011 sale a la luz una carta elaborada por una alumna de la FFL que denunciaba el acoso y maltrato de parte de un profesor de la misma escuela con el que tuvo una relación sentimental a la que ella puso fin, una de las integrantes de este grupo la buscó para ofrecerle apoyo para sortear las dificultades que enfrentaba dentro de la facultad para que su caso fuera atendido. Con este propósito se organizan reuniones en las que participan, además de las integrantes del pequeño grupo, otras universitarias que formaban parte de colectivas que tenían experiencia en la denuncia de este tipo de casos (para ver el tratamiento que se dio a éste, consultar http://noestansolas.blogspot.com/2011/08/). En el curso de las reuniones algunas acuerdan formar la REDNES, organización que desde su surgimiento se ha preocupado por dar acompañamiento a estudiantes que deciden hacer una denuncia para favorecer en ellas la fortaleza requerida al lidiar con los obstáculos que hay que vencer y así lograr que las quejas sean atendidas dentro y fuera de la institución.

La importancia otorgada en ambos grupos a la denuncia pública de la violencia contra las mujeres dentro de los espacios universitarios resulta estratégica pues con el "ruido" generado por sus formas de denuncia han abonado a poner un alto al silenciamiento, la indiferencia, la frivolización y otras formas de negación de este fenómeno adoptadas dentro de la UNAM a lo largo del tiempo. Cabe aquí considerar que fue hasta el 29 agosto de 2016 cuando por primera vez en la historia de la Universidad se reconoce públicamente la presencia de la violencia sexista dentro de esta institución y se establece un protocolo para atender las quejas en esta materia.

Respecto a la negación de hechos cuyo reconocimiento resulta perturbador o amenazante, Cohen
(2001: 1) señala que muchas historias de negación obedecen a que la gente, las organizaciones, los gobiernos o las sociedades son enfrentadas con información que resulta difícil asimilar o reconocer públicamente. Por ello, de alguna manera ésta se hace a un lado, reprime, rechaza o reinterpreta; o bien puede ser que se registre pero sus implicaciones - cognitivas, emocionales o morales - se evaden, neutralizan o racionalizan de alguna manera. Agrega en una nota que en ocasiones no hay una negación llana de algún asunto sino sólo indiferencia hacia hechos que han ocurrido desde tiempo atrás. Añade que en algunos casos no puede hablarse de olvido, pues no se puede olvidar lo que nunca se ha intentado conocer (Cohen, 2006: 2-3).

Por su lado, Rayner (2012) identifica cuatro estrategias — que pueden ser deliberadas, implícitas o inconscientes - utilizadas por las organizaciones para lidiar con conocimientos que producen incomodidad por el potencial que tienen para socavar arreglos institucionales clave o la posibilidad de alcanzar los objetivos que se persiguen; éstas son: a) rechazar la consideración o existencia de una información, es decir negarla; b) desestimar la información al poner poca atención en ésta o descartarla por errónea e irrelevante; c) generar una actividad que sirva de señuelo para distraer la atención de lo que resulta incómodo; d) desplazar la atención sobre un objeto mediante su sustitución por otro que resulta más manejable.

Sin duda, el trabajo desarrollado por los grupos de estudiantes feministas como los considerados en esta investigación han contribuido de manera importante a poner bajo la luz un "conocimiento incómodo" para el mantenimiento del orden establecido. Incomodidad que no pocas veces se refleja, como se verá más adelante, en la descalificación de quienes mediante diversas formas de protesta exhiben la violencia sexista cuya existencia se ha negado a lo largo del tiempo de variadas maneras. 


\section{Las formas de la protesta}

Para dar visibilidad a sus luchas y demandas las integrantes de estas colectivas adoptaron diversos recursos expresivos. A propósito de éstos, Scribano y Cabral (2009: 130, 131 y 136) plantean: "Cuando la voz no alcanza aparece una multiplicidad de 'medios' transformados en mensajes; emergen nuevas materialidades vueltas expresión de lo silenciado por la obviedad de lo que se denuncia, por las palabras que faltan (¿io sobran?), por las prácticas que no están, pero que son". Agregan que tales recursos son instrumentos que los sujetos eligen "para hacerse escuchar dejándose ver" y hacen posible "que propios y extraños tomen nota"; es decir, registren lo que ha quedado fuera de consideración, lo silenciado. Agregan que los recursos expresivos están vinculados al logro de la visibilidad de los sujetos a través de las formas que eligen para llevar a cabo sus protestas, "existe una puesta en escena de una demanda dentro de un campo conflictual que supone una interpelación de audiencias, con base en la construcción y selección de determinados recursos expresivos. Un recurso expresivo se puede conceptualizar, entonces, como un 'objeto textual que permite delimitar, construir y distribuir socialmente el sentido de la acción'”.

Así, para hacerse oír, las jóvenes entrevistadas adoptaron una variedad de recursos entre los que destacan, por la atención que lograron despertar: escraches,${ }^{6}$ cierres de 24 horas de la FFL, asambleas públicas en donde se explicitaba que los hombres no tenían voz ni voto, "tendederos", 7 el uso de las redes sociales y otros recursos digitales para difundir sus protestas y convocar a sus actividades.
Si bien el acoso sexual y otras formas de violencia sexista "Es un mal con el que se ha aprendido a vivir [por lo cual] nadie hace nada" — señaló una estudiante en una entrevista previa a esta investigación-, las protestas organizadas por las colectivas en cuestión abonaron a alterar tal normalidad. Cabe aquí considerar, como señala Scribano (2013: 101), que "Los mecanismos de soportabilidad social del Sistema $[\ldots]$ operan 'casi desapercibidamente' en la porosidad de la costumbre, en los entramados del común sentido, en las construcciones de las sensaciones que parecen lo más 'íntimo' y 'único' que todo individuo posee en tanto agente social".

Un indicador de las formas en que estas colectivas trastocaron "la normalidad"8 que da cobijo a la violencia sexista es la intensa polémica despertada por sus protestas; no solo por lo que denunciaban sino también, de manera importante, por los recursos expresivos adoptados. Por ejemplo, la primera asamblea organizada por la AF - en un espacio ubicado a la entrada de la FFL para forzar que quienes ingresaban y salían de la escuela escucharan sus denuncias - generó airados reclamos (gritos y rechiflas) de parte de un buen número de varones y algunas mujeres debido a que, a pesar de su insistencia, se impidió a los hombres hacer uso de la palabra, "si ustedes tienen tanto qué decir pues entonces vayan a su asamblea y díganlo. Ahorita nosotras nos estamos organizando y éste es nuestro espacio. Ustedes ya tienen un montón de espacios, así que déjennos hablar a nosotras. Y ya que están aquí: escuchen, aprendan y iya! O sea, no tienen por qué intervenir" (Luisa).

\footnotetext{
6 "Escrache. Manifestación popular de protesta contra una persona, generalmente del ámbito de la política o de la Administración, que se realiza frente a su domicilio o en algún lugar público al que deba concurrir" < https://dle.rae.es/escrache>. "Escrache es el nombre dado en Argentina, España, Paraguay, Uruguay y Venezuela a un tipo de manifestación en la que un grupo de activistas se dirige al domicilio, lugar de trabajo o en lugares públicos donde se reconozca a alguien a quien se quiere denunciar" < https://es.wikipedia.org/ wiki/Escrache>.

${ }^{7}$ El tendedero tiene como antecedente la pieza de la artista feminista Mónica Mayer presentada por primera vez en 1978 en el Museo de Arte Moderno de la Ciudad de México. Para la elaboración de éste se pidió que las mujeres escribieran en pequeñas papeletas lo que más detestaban de la ciudad. La mayoría de las respuestas giraron en torno a la violencia sexual en las calles y el transporte público (véase Mayer, 2015 y 2017).

${ }^{8}$ Respecto a la normalización de la violencia y las dificultades que esto ofrece para tener una visión cabal de este fenómeno dentro de las universidades, véase Evangelista, 2019.
} 
Al finalizar la asamblea se invitó a las asistentes a escribir en papeletas las experiencias de acoso que habían vivido en la FFL el nombre de los agresores y ponerlas en un tendedero para exhibir lo que ocurría en la escuela. Sofía comenta:

Creímos que nadie iba a acceder $[\ldots]$ pero nos empezaron a dar hojas con los nombres y lo que habían hecho; ¡fue increíble! [...] mientras cargábamos el tendedero de las denuncias marchábamos por todos los pisos [...] me acuerdo que éramos como unas 20 porque hacíamos ¡mucho ruido! y fue super divertido, fue muy catártico ¡fue genial! [...] Abrimos una página en Facebook y un montón de chicas seguían denunciando.

El ámpula que levantó esta asamblea en la comunidad de la FFL y la visibilidad que dio a la AF se aprecia en la carta que publicó en su página de Facebook un docente: "A lo largo de la semana, he leído una gran cantidad de respuestas al tendedero y a la organización de la asamblea, la gran mayoría acusan a las organizadoras y participantes de difamación, de carecer de sentido común, de sectarismo, de 'feminazismo', entre otras cosas" (Cruz Arzabal, 2016).

Respecto al efecto de sus protestas Sofía señaló que la visibilidad que lograron condujo a otros grupos feministas de la Universidad a dar apoyo a sus acciones; también dijo:

Yo creo que [nuestro trabajo] logró visibilizar qué está pasando; o sea, que algo que siempre ha pasado que es el acoso y la violencia como sistemática hacia las mujeres, pero que siempre fue como algo en secreto ¿no?, como de... "a ella le tocaron las piernas" o... "este profesor todo el mundo sabía que era un acosador y nadie hacía nada" ¿no? Entonces lo que hizo fue evidenciar qué pasa ¿no?, que la Universidad no se salva por ser el lugar sagrado del conocimiento ¿no? sino que en la Universidad hay un montón de violencia, que las estudiantes la viven, las maestras lo viven, las trabajadoras lo viven y creo que [exhibir] eso fue como el ¡bum!.

El escrache es uno de los recursos que ha privilegiado la REDNES para denunciar públicamente casos en los que las quejas presentadas por alumnas no recibieron respuesta adecuada o fueron obstaculizadas por quienes debían atenderlas (véase Barreto 2018, 2017; González, 2019). El éxito de las denuncias de esta colectiva se aprecia no sólo en el curso favorable que éstas tomaron, sino también en el efecto reparador para las afectadas de la escucha y el apoyo recibidos de otras mujeres, de su participación en la preparación colectiva de las acciones para llevar a cabo la denuncia, de la liberación emocional favorecida por el hecho de realizar las denuncias arropadas por la experiencia de no estar solas. Por ejemplo, una joven señaló 'Fíjate que antes del 'escrache' lo soñaba mucho agrediéndome, persiguiéndome, eran pesadillas [...] Después del 'escrache' ya no he soñado nada así. Es una sanación y también dejé de tenerle miedo. Fue una apropiación del territorio [la facultad] que no tiene que ver con la justicia legal" (Barreto, 2017: 278).

A partir de los comentarios recibidos respecto a la importancia de los escraches para quienes recurren a éstos después de no haber tenido respuesta sus denuncias formales, Elvira señaló: "O sea, de verdad sintieron como muy liberador el hecho de gritar el nombre del acosador y de que se enteraran de lo que hizo ¿no?, porque no es algo que se tiene que esconder. O sea, el hecho de nombrarlo, el hecho de decirlo...". Agregó que cuando les comentaban "me sorprende que aunque no las conocía, ustedes [integrantes de la $\mathrm{AF}$ ] están aquí conmigo"; a lo que respondían "Sí, estamos aquí contigo. ¡No estás sola!”

\section{"El feminismo me sacudió el alma"}

Cuando se preguntó a las estudiantes sobre lo que experimentaban cuando protestaban aludieron de distintas formas a la fuerza y satisfacción que les 
daba ser capaces de hacerse escuchar y romper el silencio sobre la violencia machista, "Tomar un espacio que no se pensaba que se podía tomar como es la facultad, el hecho de ir gritando [consignas] por los pasillos, pegar el retrato de los acosadores ¿no?” (Elvira). En el mismo sentido, Luisa señaló: “[para denunciar] no necesitamos toda esa como red de autoridades y demás, sino que nosotras mismas podemos denunciar con lo que tenemos ¿no?; o sea, con nuestras voces y todo ese ruido que nos han negado ¿no? A mí me parece fabuloso".

También aludieron al goce que les daba el ejercicio de la rebeldía y el contagio de ésta a otras mujeres que se sumaban a su causa, al placer por la incomodidad que despertaban sus reclamos "me gusta mucho que la gente se sienta muy incómoda porque ahí hay algo; en la incomodidad siempre hay algo ¿por qué te pone incómodo?" (Sofía). Asimismo, hablaron del cariño y solidaridad que experimentaban entre ellas y de la fuerza que esto les daba. También de "la alegría de estar ahí con otras, estar juntas. [Al final de un escrache] todas nos vimos y era tanta la fuerza que teníamos que sin decir nada nos vimos y todas nos abrazamos así, como formando un cuerpo" (Elvira). Junto a lo anterior, mencionaron la ansiedad y el miedo experimentados antes de iniciar las protestas por el riesgo que corrían de ser agredidas "poner el cuerpo me parece como muy fuerte porque poner el cuerpo en este país es muy peligroso ¿no?, y lo sabemos" (Elvira). También hubo referencias al cansancio que podían experimentar; en éste fue enfática Sofia: "Qué lastre y qué pesadez tener que estar haciendo esto para que la gente voltee a ver qué está pasando; o sea, tenemos que hacer este ruidero y todo este circo para que la gente diga 'um... creo que algo está pasando, creo que las mujeres están siendo agredidas' ¿no? Y sí, ¡me cansa!”.

Frente a la diversidad de emociones experimentadas por las estudiantes es necesario considerar la importancia que éstas pueden cobrar como inhibidoras - miedo y cansancio - o dinamizadoras - el goce de la rebeldía, el cariño y solidaridad entre ellas, la satisfacción por su capacidad de agencia, etcétera- de la acción política (véase Flam, 2005). Collins señala que en cualquier movimiento social hay una dinámica emocional que se genera en los rituales de interacción que los sujetos llevan a cabo "El núcleo de un ritual de interacción es el proceso en que los participantes desarrollan un foco de atención común y sus micro-rítmos corporales y emociones entran en consonancia recíproca"; entre los efectos posibles de los rituales exitosos están varias de las emociones mencionadas por las estudiantes: la experiencia de solidaridad y el sentimiento de membrecía, así como una energía emocional que se expresa en "sensación de confianza, contento, fuerza, entusiasmo e iniciativa para la acción" (Collins, 2009: 71 y 73).

La importancia de la interacción de los cuerpos para lograr la energía emocional — "una disposición a la acción"- y el contagio de ésta que requieren tener quienes participan en un ritual de interacción para poner entusiasmo en la acción (Collins, 2009: 162 y 148), también es señalada por Summers Effler (2012), quien precisa que cualquiera que haya estado en una protesta en la que se despliega un alto nivel de energía sabe que ésta puede contribuir no sólo a modificar tu mente y nivel de compromiso sino también tu vida; agrega que el componente visceral y las dinámicas corporales resultan tan cruciales para hacer sentido de algo como cualquier marco cultural que esté disponible. Por otro lado, de acuerdo con Taylor y Whittier (1995: 176), el destacado significado emocional de los rituales en las acciones colectivas obedece a que éstos son los mecanismos culturales mediante los que se expresan las variadas emociones (entusiasmo, orgullo, enojo, odios, miedo, dolor) que movilizan y sostienen los conflictos.

El importante papel dinamizador que puede cumplir el enojo en la movilización de los esfuerzos colectivos de las mujeres se aprecia no sólo en la literatura especializada sino también en los relatos de las estudiantes; por ejemplo, Elena señaló: 
Fue un dolor el que nos movió y nos puso con toda la rabia $[\ldots]$ esta sensación de "¡cómo que la violaron!” ¿no?. Es una rabia milenaria... entonces es también la sumatoria, la sumatoria de rabias que crean procesos políticos; o sea, la rabia es un impulsador increíble ¿no?, un motor de la vida que yo apenas experimento hace poco sin tanta restricción.

A propósito del enojo alimentado por el movimiento de mujeres, Jasper (2012-2013: 60) señala que éste "es una forma de justa indignación, una sensibilidad moral basada en un análisis de la injusticia tanto como en un visceral sentimiento de opresión". También señala Jasper (2014: 210) que el enojo abre el camino hacia la indignación, el orgullo y otros ingredientes de la asertividad. Hochschild (2003: 173) anota que debido a que las reglas que regulan la expresión de las emociones - feeling rules - están marcadas por órdenes sociales como el de género, el enojo adquiere una connotación distinta cuando lo expresa un hombre o una mujer. Así, mientras en el caso de los varones tal emoción no es vista como debilidad de carácter sino como una respuesta "racional" o entendible e indica la posesión de fuertes convicciones, en las mujeres se considera como un signo de inestabilidad que no está vinculado a eventos reales pues sus reacciones son interpretadas con base en la emocionalidad que se les atribuye como característica. A partir de estos señalamientos, la autora concluye que "mientras menor sea nuestro estatus, nuestra manera de ver y sentir está más sujeta a ser desacreditada y se vuelve menos creíble" (para una visión de los debates sobre el enojo dentro del feminismo, consúltese Holmes, 2004).

Por su lado, Lyman (2004) plantea que el enojo es una emoción política indispensable pues sin el discurso del enojo el campo político se quedaría sin la voz de quienes carecen de poder. Así, cuando el enojo es tomado como una forma de comunicación y no como un desorden psicológico o comportamiento incivil, puede darse un diálogo público intenso pero constructivo respecto a la justicia del orden dominante. El autor agrega que una de las dificultades para el reconocimiento del valor político del enojo es que ha sido construido como un problema de carácter psicológico. Esto conduce a la descalificación - falta de control, emocionalismo, neurosis - de quienes reaccionan con enojo, así como a ignorar las relaciones sociales y posibles injusticias que despiertan esta emoción; es decir, la psicologización del enojo es una forma de silenciamiento del malestar de los oprimidos.

La patologización del enojo de las mujeres, en particular de las feministas, para deslegitimizar su malestar y luchas es un hecho común que se advierte en los epítetos utilizados para referirse a ellas - histéricas, locas, feminazis, paranoicas, etcétera-, así como en el tipo de comentarios que circularon en redes sociales y medios digitales como reacción a las protestas llevadas a cabo por las colectivas de las entrevistadas; por ejemplo:

Me da tristeza ver a estas pobres chicas que cegadas por la paranoia están camino de convertirse en mujeres amargadas, viviendo y sumándose al miserable feminismo (Miranda, 2016).

Estamos a tiempo de frenar a las feminazis antes de que su movimiento domine la facultad. Un simple comentario en Facebook es suficiente para que se organicen y ataquen con gritos de monos aulladores. ${ }^{9}$

Cómo me gustaría verlas encerradas en una celda aisladas del resto del mundo donde nadie tenga que seguir oyendo sus locuras (SDP Noticias, 2016).

El temor que despierta la insubordinación de las estudiantes contra el orden de cosas, así como contra la tradicional sordera institucional frente a sus

\footnotetext{
${ }^{9}$ https://www.facebook.com/Feministas-de-FFyL-1537475649892416/ [Consulta: noviembre de 2016].
} 
reclamos, las expone a agresiones de diversos tipos con las que se busca amedrentarlas y desalentar sus acciones. Esto se aprecia en un comunicado de mayo de 2017 firmado por Mujeres Organizadas de la FFL en el que, entre otras cosas, se señala que después de una intervención que se llevó a cabo en los alrededores de la Facultad de Ingeniería para visibilizar la violencia contra las mujeres, "la respuesta dada en redes sociales [Grupo de Facebook IngenierosUNAM] fue demasiado violenta con comentarios despectivos que iban desde nombrarnos 'feminazis, locas, exageradas, etcétera' hasta amenazas de muerte 'Deberíamos meterlas en un cuarto y quemarlas a todas $" .{ }^{10} \mathrm{El}$ miedo que pueden despertar las agresiones que se les dirigen se muestra en el relato que me compartió una estudiante:

Un chico me atacó en las escaleras de la Biblioteca Central [...] me alzó el vestido y me pasó así... la mano, a las 10 de la noche [...] y no lo alcanzamos [ella y otras estudiantes que lo perseguían]. Entonces, este $[\ldots]$ al día siguiente de eso le platiqué a la Asamblea [Feminista], y la Asamblea lo empezó a denunciar y yo también; después de eso como diez cuentas de Twitter me dijeron que me iban a venir a buscar a la facultad para corregirme. Entonces, al día siguiente de eso yo llegué muerta de miedo a la facultad y me encontré a [una compañera de la $\mathrm{AF}$ ] y le conté así, llorando. Me abrazó con una ternura impresionante y me dijo "Yo también lo he vivido y sé el miedo que tienes en este momento, pero ¡no estás sola, no estás sola!”.

Hercus (2005) identificó dos tipos de trabajo emocional adoptados por las mujeres para lidiar con las reacciones - que transitan de lo defensivo a la agresión abierta - que genera el activismo feminista debido a que suele interpretarse como un comportamiento desviado. Reacciones de parte de quienes funcionan como agentes de control; por ejemplo, parejas, compañeros de trabajo y amistades. La primera modalidad es la autorestricción que se expresa en una selectividad de las ideas feministas de las que se habla o en abstenerse de dar sus opiniones para evitar reacciones adversas y conflictos; la segunda se da cuando las ideas feministas se expresan de manera asertiva y con confianza y funciona como una estrategia tanto para educar a quienes escuchan como de autodefensa. La autora agrega que entre los costos asociados con el trabajo emocional requerido para negociar la identidad feminista, las participantes en su investigación identificaron estrés, fatiga emocional, culpa, auto alienación (self-estrangement) y frustración. Hercus precisa que para muchas de sus informantes la experiencia cotidiana de suprimir el enojo o ser ridiculizadas por expresarlo contribuían a una disminución de la energía emocional. En contraste con los costos señalados, las mujeres mencionaron que su participación en marchas y otros eventos feministas les permitía reponer energías, afirmar su identidad feminista, tomar fuerza para continuar sus luchas y tener la oportunidad de mostrar las emociones consideradas como desviadas para las mujeres.

El cansancio que puede generar el activismo se hizo presente no sólo en Sofía sino también en algunas otras. El denominador común era el desgaste emocional generado por la conexión que establecían con quienes se acercaban a ellas para relatar sus experiencias y solicitar su orientación y apoyo. Relatos en los que se hacían presentes emociones - como dolor, vergüenza, miedo, angustia, indefensión - que las tocaban con mayor o menor intensidad y a los que sumaban las noticias sobre feminicidios en los que la crueldad alcanzaba límites insospechados. Asimismo, el cansancio se relacionaba con la forma en que toda esa violencia las confrontaba con la necesidad de reconocer la existencia de un orden opresivo "gigante"

\footnotetext{
${ }^{10}$ https://www.facebook.com/MujeresOrganizadasFFyL/posts/116629968845704?_tn__=K-R, (Consulta: agosto de 2017).
} 
al que había que combatir de manera incansable pues tenía mil formas de recomponerse; lo que llevaba a algunas a dudar de la eficacia de sus formas de lucha. "Yo sé que todo esto va para largo, pero... cansa muchísimo, mucho, mucho, mucho [...] tantas marchas, estar viendo diario feminicidios; o sea ite cansas! Me cansa, me da miedo; o sea, si no te pones un escudo todo te atraviesa, te rompe y no puedes ir a la lucha si tú estás hecha pedazos por dentro, entonces acabas cansada, muy cansada" (Sofía).

\section{Trabajo emocional}

Como se aprecia en la variedad de emociones experimentadas por las activistas a las que se aludió en párrafos anteriores, en su práctica coexisten las que les generan la energía emocional necesaria para dar impulso a sus acciones (rebeldía, cariño, solidaridad, alegría, enojo, etcétera) con las que les restan energía (miedo, cansancio emocional). Respecto a las últimas, es necesario considerar el señalamiento de Collins (2009: 46-47) en relación con el peso que adquieren para la superación de éstas la energía emocional que se va acumulando en las distintas interacciones que producen experiencias favorables; lo que sucedía a las estudiantes que mencionaron su cansancio, "[el cariño] alienta mucho, mucho, mucho. Alienta porque sientes un sostén, una red más grande, más allá de ti”, dijo Margarita. Más adelante señaló "no queremos ser cuerpos tristes, cuerpos víctimas, porque los cuerpos tristes son más objeto de opresión; uno no se puede defender. [...] El espacio feminista ha sido un lugar de mucha convivencia solidaria y de alegría también. Esto es muy importante pues cambia las formas de hacer política".

Precisamente una de las labores que suelen cumplir los grupos feministas como los aquí considerados es el trabajo emocional que desarrollan con las afectadas por la violencia para que no se queden atrapadas en imágenes negativas de sí mismas y en aquellas emociones - como el temor y la culpa- que merman su capacidad de hacer frente a los comportamientos opresivos. Taylor y Whittier (1995: 178) señalan que los grupos feministas buscan a través de diversas acciones canalizar las emociones vinculadas a la subordinación de las mujeres (miedo, vergüenza, depresión) hacia otras que conducen a la protesta y al activismo, como sucede con el enojo. Respecto a la necesidad de intervenir en la esfera de la subjetividad de quienes ocupan una posición subalterna, Rolnik (2019: 118) señala que nada garantiza que quienes están en tal situación "sean, por principio, agentes potenciales de insubordinación micropolítica, ya que su subjetividad puede estar bajo el hechizo del inconsciente propio del régimen dominante, aunque lo combatan macropolíticamente", Gould (2009) destaca la importancia que cobra dentro los movimientos sociales la pedagogía emocional que adoptan - muchas veces de manera no premeditada - para generar un nuevo habitus emocional que permita a quienes participan en éstos desarrollar sentimientos diferentes sobre sí mismos, sobre la sociedad dominante y sobre sus posibilidades políticas. Agrega que este tipo de trabajo emocional es menos visible que otras tareas que emprenden los movimientos; sin embargo, si se pone atención a su retórica y acciones, la dimensión emocional de su trabajo se ilumina.

En el caso del movimiento feminista el trabajo emocional ha sido clave para su desarrollo. Los llamados grupos de conciencia o pequeños grupos que formaron mujeres inconformes con el trato sexista que recibían en diversos movimientos - ocurridos en los años sesenta del pasado siglo y posteriores de parte de sus compañeros de lucha, dieron un fuerte impulso al resurgimiento del movimiento feminista. La participación de las mujeres en estos grupos, la posibilidad que les daban de hablar de sus malestares, de explorar asuntos íntimos, de externar emociones como su enojo sin temer consecuencias: les permitió identificar que lo que ellas consideraban como problemas de orden personal eran en realidad asuntos de carácter social (Gordon, 2016: 115-117). 
Señala Gordon que a partir del develamiento que se dio en estos grupos de que lo que hoy se llama sistema de género era responsable de mucho de lo que experimentaban, las mujeres desarrollaron una subjetividad y una identidad política que dieron las bases para un nuevo activismo. Staggenborg y Taylor (2005: 46) puntualizan que "los movimientos contemporáneos de mujeres siguen combinando marchas masivas, acción directa y acciones políticas convencionales con desarrollo de la conciencia, autoayuda y formas culturales, performativas y discursivas de resistencia orientadas al cambio social y cultural". Greer (2001: 505) precisa: "Lo personal sigue siendo político. La feminista del nuevo milenio no puede dejar de ser consciente de que la opresión se ejerce en y a través de sus relaciones más íntimas, empezando por la más íntima de todas: la relación con el propio cuerpo".

El reconocimiento de que "lo personal es político" y la pedagogía emocional que deriva de esto se hace presente de diversas maneras en el trabajo llevado a cabo por los grupos en cuestión. Un buen ejemplo de esto es el acompañamiento dado a quienes solicitaban su apoyo. Teresa señaló que cuando alguien acudía a ellas, buscaban estar presentes en las entrevistas "dos o tres de nosotras para que se sientan acompañadas"; se les trataba con calidez; las escuchaban sin juicio y sin poner en duda su palabra; daban cabida a la expresión de sus emociones, lo que favorecía una liberación emocional; les precisaban las acciones con las que podían apoyarlas, dejándoles siempre a ellas la decisión de lo que se haría; "las integramos a las reuniones de la Red y les damos espacio para que hablen; después hacemos una reflexión como la del pequeño grupo". Más adelante señaló, "son reuniones que te dejan emocionalmente muy cansada de estar escuchando [...] te dejan muy cansada; o sea, es un trabajo emocional [muy fuerte]".

En la entrevista realizada a una joven que fue apoyada por la REDNES, señaló - con la voz quebrada por momentos de llanto- que su experiencia con el grupo la había marcado pues:

[Era] como saber de pronto que podía tener un respaldo con alguien si me volvía a pasar algo. Era como eso, como justo eso, ¡no sentirse sola!, ¡no estar sola! y eso fue...[Ellas] me dan fuerza... A veces [cuando las busco] no sé qué decirles, pero... simplemente estar ahí... Creo que eso es lo más importante que me han dado y que no se documentan más que las protestas, pero... esa experiencia... y los vínculos... Yo he tenido amigas que.... pero siempre está como... este juzgarte ¿no?... y de pronto es bueno sentir que no te juzgan, sentir que no es tu culpa. Ésa es como la experiencia que para mí ha sido muy importante ¿no?, que la puedes regar... yo tuve una situación de violación y pensaba que había sido por mi culpa porque estaba borracha... y llegar ahí y saber que no, que otras te entienden... porque a lo mejor le platicaste a tu amiga y te dijo "es que para qué bebiste", y tú sentirte mal, yo estaba muy mal. Y de pronto llegar y ver que ¡no!, que todas lo vivimos, que todas estamos en eso y que no es nuestra culpa es..., es muy bueno ite fortalece! y te hace dejar de sentirte insegura, y sucia, y mala, y culpable, y que mereces otras cosas.

La importancia concedida por las entrevistadas a la labor emocional con quienes buscaban su apoyo contrasta con la otorgada a lo experimentado por ellas como resultado de su trabajo. Si bien dijeron compartir actividades de esparcimiento y sentirse sostenidas por sus compañeras cuando atravesaban momentos difíciles, hay un trabajo cuya ausencia resultó notoria: incorporar en sus colectivas una reflexión emocional de carácter sistemático que les permitiera tomar conciencia de las emociones que intervienen en la vida de sus grupos y de sus integrantes, así como buscar formas de trabajarlas (véase Brown y Pickerill, 2009; King, 2005); aspecto que sin duda contribuía al cansancio referido por algunas. 
En la reflexión de Elvira respecto a lo sucedido cuando ella y otras jóvenes intentaron formar una colectiva que contribuyera a la lucha contra los feminicidios que ocurrían en el Estado de México, habló de la depresión que varias experimentaban por la situación de violencia y por asuntos personales. Añadió que cuando se dieron cuenta de que "estábamos bien rotas", concluyeron: "si queremos trabajar con otras personas es importante que primero trabajemos con nosotras porque si no, esto no va a funcionar, y empezamos a hacer talleres entre nosotras y así formamos la colectiva y empezamos actividades afuera". Seguramente la omisión de un trabajo similar en la Asamblea Feminista fue lo que condujo a Sofia a ponerse un escudo que parece no haberle funcionado dado el profundo cansancio que experimentaba. Por su lado, Teresa dijo "Yo llevaba tres casos, era demasiada carga emocional. O sea, era muy desgastante. Llegó un momento en que reventé y me solté del grupo; no totalmente, pero me di un respiro".

Así, las experiencias de violencia atendidas por estas jóvenes les despertaban emociones que no deben ignorarse sino que demandan un trabajo grupal sistemático de reflexión emocional. Trabajo que no puede dejar de lado aspectos como la inversión de energía que conlleva el ahínco puesto en sacar adelante los casos atendidos; el hecho de que su labor la ejercen desde su posición como estudiantes y no como integrantes de organizaciones de activistas que se han institucionalizado y cuentan con formación, tiempo, sueldos y otros recursos que facilitan su actividad; las tensiones que genera que el tiempo dedicado al activismo supone con frecuencia hacer a un lado las responsabilidades escolares; los malestares al interior de los grupos por asuntos como la sobrecarga de responsabilidades en algunas o por posiciones divergentes que no se discuten mayormente. Respecto a las tensiones que se daban en los grupos, Elena dijo "A algunas nos preocupa más el cuidado de ese tejido, a otras no tanto ¿no?, pues hay otras urgencias que estar pensando en cómo nos relacionamos mientras... a las mujeres las están matando por el feminicidio o por abortos clandestinos mal hechos ino?".

A propósito de la necesidad de un trabajo de tal tipo, Rosa señaló "Creo que antes de poder accionar hacia afuera se tiene que trabajar mucho en lo interno, desde lo individual hasta lo colectivo: ¿quiénes somos?, ¿qué buscamos?, ¿cómo nos relacionamos?, ¿cuáles son nuestras posturas teóricas?”. Agregó que si no se tiene un objetivo muy claro "la banda se mueve sólo con la corriente, sólo por lo coyuntural, y se termina viendo los problemas de manera muy superficial; tanto los internos como los externos y los conflictos se empiezan a acrecentar".

Si bien en el comunicado publicado por la $\mathrm{AF}$ el 30 de marzo de 2017 para informar la disolución de esta colectiva se atribuye esta decisión al rechazo que experimentaban las organizaciones de mujeres de parte de una fracción importante de la comunidad y al "violento escrutinio" del que eran objeto, no puede ignorarse el peso que seguramente tuvo en tal medida la ausencia de un trabajo interno. En una entrevista realizada a María meses después de la disolución de la AF, comentó que lo que en realidad había ocurrido es que no habían sabido manejar sus diferencias.

\section{Reflexiones finales}

El trabajo realizado por las activistas de ambos grupos ha tenido frutos importantes. Como se recordará, la Asamblea Feminista puso el foco de atención en exhibir la variedad de formas en que la violencia machista se hacía presente en la vida diaria de la facultad, así como la necesidad de poner un alto a esta situación. Si bien la insubordinación de las estudiantes y la formación de la AF como un grupo exclusivo de mujeres obedeció inicialmente al malestar que les generaba el trato machista que recibían de parte de sus compañeros en los grupos mixtos de estudiantes que se identificaban como activistas de izquierda, fue 
en el curso de las acciones que organizaban que tomaron conciencia de la extensión que alcanzaba la violencia machista dentro de la facultad. A propósito de lo ocurrido en una de las primeras reuniones que realizaron con un buen número de alumnas de la FFL, María señaló: "Y ahí, en ese momento, nos dimos cuenta de que el asunto es bastante grave. Que no era casualidad haber detectado situaciones de violencia, que ha habido en todas las carreras: con estudiantes, con profesores o con administrativos". Junto a esto, los relatos que escuchaban y el intercambio de experiencias las llevaron a tomar conciencia de que este asunto no recibía atención de parte de las autoridades, quienes, además, a la luz del tratamiento que se daba a las denuncias, tenían como política desalentarlas (para un ejemplo del comportamiento adoptado por la entonces directora de la FFL, véase Mingo y Moreno, 2015: 150-153).

Así, el jya basta! que condujo a la formación de la AF y su traducción en diversas acciones puso bajo la luz no sólo los hechos de violencia que formaban parte de la vida diaria de las estudiantes, sino también el papel central que jugaba la institución en la perpetuación de estas conductas a través de la sofocación de las denuncias y la resistencia mostrada por sus autoridades para reconocer la existencia del problema y atenderlo. Fue así como la labor de la AF ofreció la posibilidad a un buen número de jóvenes para identificar que las experiencias de acoso vividas no debían ser asumidas como algo inevitable a lo que cada una debía hacer frente por sí sola, lo cual se hizo evidente en el número de alumnas que se acercaron a ellas para comentar sus experiencias y pedir su asesoría y acompañamiento.

Por otro lado, la disolución de la AF junto a la conciencia que tenían algunas de sus integrantes de que su paso por la Universidad tenía una temporalidad que obligaba a ocuparse de acercar a las jóvenes de nuevo ingreso a la causa feminista, condujo a varias a promover la formación de una nueva colectiva que surgió en 2017 - Mujeres Organizadas de la FFL - y que en marzo de 2018 convocó a una asamblea interuniversitaria en la que participaron numerosas estudiantes (más de 300 asistentes, según mi registro) interesadas en poner un alto a la violencia machista dentro de sus espacios universitarios. Organización que junto con otras colectivas de estudiantes feministas de dentro y fuera de la UNAM se han ocupado de dar visibilidad a este fenómeno y han logrado posicionarlo como un asunto insoslayable dentro las instituciones de educación superior, lo cual, sin duda, es muy importante - y ha llevado a la toma de ciertas medidas como el establecimiento de protocolos para dar atención a las denuncias en esta materia-; sin embargo, frente a la existencia de una cultura patriarcal tan arraigada dentro y fuera de las universidades, el camino por avanzar se avizora muy largo.

Cabe aquí destacar que el 4 de noviembre de 2019, Mujeres Organizadas de la FFL — a la que se han sumado estudiantes de los primeros semestres de esta escuela - tomaron la FFL por las mismas razones que llevaron en 2016 a las integrantes de la AF a realizar el primer paro de labores feminista. Paro que ha durado más de cuatro meses y ha adquirido gran relevancia no sólo por la amplia visibilidad que ha dado a este asunto, sino también por la fuerza que han cobrado las demandas ${ }^{11}$ de este grupo dentro y fuera de la UNAM.

A diferencia de labor desarrollada por la $\mathrm{AF}$, la Red No Están Solas ha centrado sus esfuerzos en apoyar la denuncia y resolución de casos de violencia machista lo que supone, como ya se señaló, una labor intensa de acompañamiento a quienes deciden denunciar. Si bien sus acciones públicas han contribuido a posicionar el tema en la agenda universitaria, la parte medular de su trabajo ha sido la atención prestada a casos particulares (véase Barreto y Flores,

${ }^{11}$ Para ver sus demandas, la respuesta de las autoridades y otra información sobre la toma de la FFL, https://www.facebook.com/pg/ MujeresOrganizadasFFyL/posts/; http://www.filos.unam.mx/ 
2016), algunos de los cuales han sido ampliamente conocidos gracias al uso estratégico de diversos recursos digitales de parte de la REDNES, ${ }^{12}$ así como a las conexiones tejidas con diferentes medios "buscamos hacer alianzas con distintos medios para que cuando vamos a hacer una protesta lo cubran y se viralice. También tenemos relación con chicas feministas que están en otro tipo de medios que nos dicen 'con nosotras pueden contar; cuando tengan un evento nos hablan y las apoyamos" (Estela).

Junto a la huella que dejó el trabajo de la AF en la FFL y en estudiantes no sólo de esta escuela sino también de otras — por ejemplo en la Facultad de Psicología y en la de Ciencias Políticas y Sociales, en donde se formaron colectivas feministas que se nutrieron del trabajo de esta agrupación-, así como a la que ha dejado y sigue dejando en diversas estudiantes la labor de acompañamiento desarrollada por la REDNES, es menester no dejar de lado los frutos del activismo para las integrantes de estos grupos.

De diversas maneras todas atribuyeron gran valor a su práctica feminista por los cambios experimentados en ellas debido a que, como Elsa anotó, el trabajo personal era muy fuerte "pareciera que el trabajo es de aquí hacia afuera; para nosotras sí había un trabajo interno muy fuerte". Entre los cambios señalados:

Me quitó certezas ¿no? porque yo vivía en un mundo hecho de certezas... Y cuando empiezo con el feminismo fue como "¿ahora qué hago?; o sea, si todo [lo que me dijeron que debía yo ser] no es real... y yo puedo elegir, tengo la libertad de elegir ¿qué hago? O sea, primero me quedé en un vacío tremendo ¿no? y fui construyéndome... O sea, sin el feminismo yo no sería nada de lo que soy ahora. [...] No me gusta la palabra empoderar, pero creo que es como la más cercana... me enriqueció, me llenó. [Asumirme feminista me permitió afirmar] ¡sí, yo puedo decir y mi voz es válida, y mi voz va a ser escuchada! (Rosa).

Y me sentía muy culpable ¿no?; así, muy culpable, porque decía que yo todo lo había hecho ¿no?, que era mi culpa y que era yo tonta “¿cómo es posible que te dejes si es evidente que es violento?" Y ya, entonces con el feminismo pues aprendí como a valorarme y sobre todo aprendí... que la violencia lo que hace es que, entre otras cosas, te aísla y hace como esto de que te sientas culpable ¿no? de la situación que estás viviendo y... creo que me dio muchas herramientas ¿no? (Elvira).

[En ocasiones] yo tengo esa sensación en los pies, como que mis pies son más firmes... Siento como si mi pisada fuera más..., más firme, más dura, más potente... [Cuando tenemos un logro] me repara algo de mí, de lo que yo también..., de lo que a mí también me duele y también me da coraje [...] Ver cómo ellas actúan a mí me da fuerza... para decirle a alguien de frente “iSabes qué, esto no me parece!, ¡no me gusta!, ¡no estoy de acuerdo eh, no te permito que pases de esto!". Y digo, y lo pienso, "Fulana el otro día lo hizo así ¡y yo también puedo hacerlo!”, ¿̇no? [...] Y eso... repara y te fortalece, te fortalece. Vas perdiendo el miedo, porque sí da miedo, sí da miedo, sí da miedo hablar, sí da miedo denunciar, sí da miedo [...] Cada vez que veo lo que hacemos me siento fuerte y me siento valiente y... y eso me gusta (Estela).

Los cambios operados en estas jóvenes llevan a considerar lo señalado por Rolnik (2019) respecto a la necesidad que tienen, quienes están en una situación de opresión, de disolver los personajes que dan sostén a las relaciones de poder opresivas. Dice la autora que tal disolución, así como el proceso de creación de nuevos personajes, se da en el espacio de la insurgencia micropolítica, en donde los agentes cooperan en la construcción de lo común y se

\footnotetext{
${ }^{12}$ En noviembre de 2019 su página de Facebook registraba que las seguían 24545 personas (https://www.facebook.com/rednoestansolas.rednes/, Consulta 6 de noviembre de 2019). Para un listado de las direcciones en donde se puede acceder a las publicaciones digitales de la REDNES, véase Barreto y Flores, 2016; González, 2019.
} 
aproximan por la "vía de la resonancia intensiva que se da entre frecuencias de afecto (emociones vitales)". Agrega que en este espacio se trata de tejer redes de conexiones entre sujetos que se unen a partir de "los embriones de mundo que habitan sus cuerpos" y de la urgencia de crear las formas en que tales mundos puedan materializarse (Rolnik, 2019: 128). En palabras de Preciado (2019: 14), se trata de "la gestión colectiva y creativa del malestar para permitir la germinación de otros mundos".

\section{A manera de cierre}

Las movilizaciones realizadas por diversos grupos de estudiantes feministas para mostrar su hartazgo por las variadas formas de violencia machista a las que están expuestas en sus universidades nos muestran una cara de las IES que contradice los discursos sobre la apertura, el respeto, el pensamiento crítico y otras virtudes que nos dicen se cultivan en estas instituciones. El menosprecio que en los hechos muestran tener por este asunto quienes tienen la responsabilidad de cuidar que dentro de estas escuelas, las estudiantes, como cualquier otro integrante de estas comunidades, puedan disfrutar de un ambiente amable y respetuoso en donde, a diferencia de lo que hoy sucede, el hecho de ser mujeres no las ponga en riesgo de sufrir violencia; hace evidente la urgente necesidad de que estas instituciones inicien un proceso de profunda autocrítica que les permita identificar las variadas formas en que contribuyen al sostenimiento de lo que a nivel discursivo dicen reprobar. Sin un ejercicio de esta naturaleza las medidas que se tomen - por ejemplo, el establecimiento de protocolos para atender denuncias en esta materia - escasamente contribuirán a la necesaria erradicación de un problema cuya magnitud y pervivencia reflejan el arraigo de la cultura patriarcal en estas instituciones. 


\section{Referencias}

Ahmed, Sara (2015), Sexual Harassment, <https://feminist killjoys.com/2015/12/03/sexual-harassment/>.

AHRG (Australian Human Rights Commission) (2017), Change the course: National report on sexual assault and sexual harassment at Australian universities, Sidney, Australian Human Rights Commission, <https://www.humanrights. gov.au/sites/default/files/document/publication/ AHRC_2017_ChangeTheCourse_UniversityReport. $\mathrm{pdf}>$.

Barreto, Magali (2018), "Testimonio, egunda victimización y reparación. Movilización feminista frente a un caso de violación sexual en la universidad", Sexualidad, Saludy Sociedad-Revista Latinoamericana, núm. 29, pp. 215-234.

Barreto, Magali (2017), "Violencia de género y denuncia pública en la Universidad", Revista Mexicana de Sociología, vol. 79, núm. 2 (abril-junio), pp. 261-286.

Barreto, Magali y Natalia Flores (2016), "Institucionalización, violencia de género y demandas desde la base", Nómadas, núm. 44, pp. 201-217.

Bourdieu, Pierre (1999), Razones prácticas. Sobre la teoría de la acción, Barcelona, Anagrama.

Braun, Virginia y Victoria Clarke (2012), "Thematic Analysis", en H. Cooper, P.M. Camic, D.L. Long, A.T. Panter, D. Rindskopf y K.J. Sher (eds), APA Handbook of Research Methods in Psychology, vol. 2: Research Designs: Quantitative, qualitative, neuropsychological, and biological, Washington, American Psychological Association, pp. 57-71.

Brown, Gavin y Jenny Pickerill (2009), "Space for emotion in the spaces of activism", Emotion, Space and Society, vol. 2, núm. 1, pp. 24-35.

Buquet, Ana, Jennifer Cooper, Araceli Mingo y Hortensia Moreno (2014), Intrusas en la universidad, México, Universidad Nacional Autónoma de México (UNAM), <http://www.iisue.unam.mx/libros/?ddproduct=intrusas-en-launiversidad-2>.

Cantor, David, Bonnie Fisher, Susan Chibnall, Reanne Townsend, Lee Hyunshik, Carol Bruce y Gail Thomas
(2015), Report on the AAU Campus Climate Survey on Sexual Assault and Sexual Misconduct, Washington, Westat, <https://www.aau.edu/sites/default/files/\%40\%20 Files/Climate\%20Survey/AAU_Campus_Climate_ Survey_12_14_15.pdf>.

Cohen, Stanley (2001), States of denial. Knowing about atrocities and suffering, Boston, Polity Press.

Collins, Randall (2009), Cadenas rituales de interacción, Barcelona, Anthropos.

Cruz Arzabal, Roberto (2016), "A propósito de la Asamblea Feminista", <https://m.facebook.com/ notes/roberto-cruz-arzabal/ante-la-asambleafeminista-bela-ffyl/10154113593961287/> [Consulta: junio de 2016].

Dick, Kirby (2015), The hunting ground, <https://www. netflix.com/mx/title/80036655> [Consulta: mayo de $2017]$.

Evangelista, Angélica Aremy (2017), "Hostigamiento y acoso sexual en ámbitos de educación superior del sureste mexicano", Investigação Qualitativa em Ciências Sociais, vol. 3, pp. 336-341.

Evangelista, Angélica Aremy (2019), "Normalización de la violencia de género cómo obstáculo metodológico para su comprensión", Nómadas, núm. 51, pp. 85-97, DOI: 10.30578/nomadas.n5la5.

Feltes, Thomas (2012), Gender-based violence, stalking and fear of crime. EU Project 2009-2011, <http://docplayer. net/2259902-The-project-was-financed-by-the-eucommission-for-36-months-in-2009-2011.html> [Consulta: mayo de 2018].

Fernández, Ana María (1993), "De lo imaginario social a lo imaginario grupal”, en A. M. Fernández y J. C. de Brasi (comps.), Tiempo histórico y campo grupal. Masas, grupos e instituciones, Buenos Aires, Nueva Visión.

Flam, Helena (2005), "Emotions' map", en H. Flam y D. King (eds.), Emotions and social movements, Londres, Routledge, pp. 19-40.

Fuentes, Lya Yaneth (2019), "CCuentos que no son cuentos': acoso sexual, violencia naturalizada en las 
aulas universitarias", Nómadas, núm. 51, pp. 135-153, DOI: 10.30578/nomadas.n5la8.

Fuentes, Lya Yaneth, Betulia Jiménez y Carlos Felipe Villar (eds.), (2019) "Violencias de género en las universidades", Nómadas, núm. 51, <http://nomadas. ucentral.edu.co/index.php/en/inicio/2561-violenciasde-genero-en-las-universidades-nomadas-51/1030violencias-de-genero-en-las-universidades-nomadas-51>.

Gilmore, David (2001), Misogyny: The male malady, Philadelphia, University of Pennsylvania Press.

González, Gema (2019), "Acciones colectivas para enfrentar la violencia de género en las universidades: el caso de los escraches en la Red No Están Solas", Tesis de Maestría en Estudios Políticos, México, UNAMPosgrado en Ciencias Políticas y Sociales.

Gordon, Linda (2016), "Participatory democracy from SNCG through Port Huron to women's liberation to occupy: strengths and problems of prefigurative politics", en Tom Hayden (ed.), Inspiring participatory democracy: student movements from Port Huron to today, Nueva York/Londres, Routledge, pp. 103-126.

Gould, Deborah (2009), Moving politics: emotion and act up's fight against AIDS, Chicago, University of Chicago Press.

Greer, Germanie (2001), La mujer completa, Barcelona, Kairós.

Hercus, Cheryl (2005), Stepping out of the line. Becoming and being feminist, Nueva York y Londres, Routledge.

Héritier, Françoise (2007), Masculino/femenino II. Disolver la jerarquía, Buenos Aires, Fondo de Cultura Económica.

Hochschild, Arlie (2003), The managed heart: commercialization of human feeling, Berkeley, University of California Press.

Holland, Jack (2010), Una breve historia de la misoginia/El prejuicio más antiguo del mundo, México, Océano.

Holmes, Mary (2004), "Feeling beyond rules: politicizing the sociology of emotion and anger in feminist politics", European Fournal of Social Theory, vol. 7, núm. 2, pp. 209-227

Jasper, James (2012-2013), "Las emociones y los movimientos sociales: veinte años de teoría e investigación", Revista Latinoamericana de Estudios sobre Cuerpos, Emociones y Sociedad, núm. 10, año 4, pp. 48-68.
Jasper, James (2014), “Constructing indignation: anger dynamics in protest movements", Emotion Review, vol. 6, núm. 3, pp. 208-213.

King, Debra (2005), "Sustaining activism through emotional reflexivity", en H. Flam y D. King (eds.), Emotions and social movements, Londres-Nueva York, Routledge, pp. 149-169.

Lyman, Peter (2004), "The domestication of anger. The use and abuse of anger in politics", European Fournal of Social Theory, vol. 7, núm. 2, pp. 133147, <https://journals.sagepub.com / doi / pdf/10.1177/1368431004041748>.

Mayer, Mónica (2015), "El tendedero: breve introducción", 19 de octubre, recuperado de: <http:// pintomiraya.com/redes/archivo-pmr/el-tendedero/ item/203-el-tendedero-breve-introducci $\% \mathrm{C} 3 \% \mathrm{~B} 3 \mathrm{n}$. html>.

Mayer, Mónica. (2017), "Si tiene dudas... pregunte", 11 de enero de, recuperado de: <http://pregunte. pintomiraya.com/index.php/la-obra-viva/si-tienedudas/itemlist/tag/arte $\% 20$ feminista, $\%$ 20arte $\% 20$ contempor $\% \mathrm{C} 3 \%$ Alneo, $\% 20$ arte $\% 20 \mathrm{y} \% 20$ acoso, $\% 20$ M\%C3\%B3nica\%20Mayer,\%20MUAC, \%20El\%20 Tendedero $>$.

Millet, Kate (1995), Política sexual, Madrid, Cátedra.

Mingo, Araceli y Hortensia Moreno (2015), "El ocioso intento de tapar el sol con un dedo: violencia de género en la universidad", Perfiles Educativos, vol. XXXVII, núm. 148, pp. 138-155, <http://www.iisue.unam.mx/perfiles/ index. php?numero $=148 \&$ anio $=2015>\quad$ [Consulta: octubre de 2015].

Miranda, Perla (2016), "Marchan en la UNAM contra violencia a las mujeres", El Universal, Septiembre 2, <https://www.eluniversal.com.mx/articulo/metropoli/ cdmx/2016/09/2/marchan-en-la-unam-contraviolencia-las-mujeres> [Consulta: septiembre de 2016].

National Academies of Sciences, Engineering, and Medicine (2018), Sexual harassment of women: climate, culture, and consequences in Academic Sciences, Engineering, and Medicine, Washington, DG, The National Academies Press, <https://doi.org/10.17226/24994>. 
Phipps, Alison (2018), "Reckoning up: sexual harassment and violence in the neoliberal university", Gender and Education, pp. 1-17, DOI:10.1080/09540253.2018.14824 13 [Consulta: mayo de 2019].

Phipps, Alison (2017), "Speaking up for what's right: politics, markets and violence in higher education", Feminist Theory, vol. 18, núm. 3, pp. 357-361, DOI: $10.1177 / 1464700117722001$.

Phipps, Alison (2016), "Disclosure and exposure in the neoliberal university", <https://genderate.wordpress. com/2016/05/18/disclosure-and-exposure/> [Consulta: mayo de 2019].

Preciado, Paul (2019), "La izquierda bajo la piel. Un prólogo para Suely Rolnik", en S. Rolnik, Esferas de la insurrección. Apuntes para descolonizar el inconsciente, Buenos Aires, Tinta Limón Ediciones, pp. 19-24.

Rayner, Steve (2012), "Uncomfortable knowledge: the social construction of ignorance in science and environmental policy discourses", Economy and Society, vol. 41, núm. 1, pp. 107-125, DOI: 10.1080/03085147.2011.637335.

Rolnik, Suely (2019), Esferas de la insurrección. Apuntes para descolonizar el inconsciente, Buenos Aires, Tinta Limón Ediciones.

Scribano, Adrián (2013), "Sociología de los cuerpos/ emociones", Revista Latinoamericana de Estudios sobre Cuerpos, Emociones y Sociedad, núm. 10, año 4, pp. 93-113.

Scribano, Adrián y Ximena Cabral (2009), "Política de las expresiones heterodoxas: el conflicto social en los escenarios de las crisis argentinas", Convergencia. Revista de Ciencias Sociales, vol. 16, núm. 51, pp. 129- 155.
SDPnoticias (2016), "Confrontan a profesor de la UNAM que descalificó movilizaciones feministas", SDPnoticias, noviembre 25, <https://www.sdpnoticias.com/local/ ciudad-de-mexico/2016/11/25/video-confrontan-aprofesor-de-la-unam-que-descalifico-movilizacionesfeministas $>$ [Consulta: diciembre de 2016].

Staggenborg, Susan y Verta Taylor (2005), "Whatever happened to the women's movement?", Mobilization: An International fournal, vol. 10, núm. 1, pp. 37-52.

Summers Effler, Erika (2012), "Bringing the body [back] in: where the action really is", Mobilizing Ideas, <https://mobilizingideas.wordpress.com/2012/ 12/20/BRINGING-THE-BODY-BACK-IN-WHERETHE-ACTION-REALLY-IS/\#MORE-4432>.

Taylor, Verta y Nancy Whittier (1995), "Analytical approaches to social movement culture: the culture of the women's movement", en Hank Johnston y Bert Klandermans, (eds.), Social Movements and Culture, Minneapolis, University of Minnesota Press, pp. 163-187. Vidu, Ana, Rosa Valls, Lidia Puigvert, Patricia Melgar y Mar Joanpere (2017), "Second order of sexual harassment-SOSH", Multidisciplinary fournal of Educational Research, vol. 7, núm. 1, pp. 1-26, DOI: 10.17583/remie.2017.2505.

Whitley, Leyla y Tiffany Page (2015), "Sexism at the centre: locating the problem of sexual harassment", New Formation, núm. 86, pp. 34-53, <https://www. lwbooks.co.uk/new-formations/86/sexism-at-centrelocating-problem-of-sexual-harassment>.

\section{Cómo citar este artículo:}

Mingo, Araceli (2020), “Juntas nos quitamos el miedo'. Estudiantes feministas contra la violencia sexista”, Revista Iberoamericana de Educación Superior (RIES), vol. XI, núm. 31, pp. 3-23, DoI: https://doi.org/10.22201/iisue.20072872e.2020.31.703 [Consulta: fecha de última consulta]. 